\title{
Planejamento e Controle orçamentário empresarial como Ferramenta de Apoio à Tomada de Decisão
}

\author{
Carlos Eduardo Facin Lavarda \\ Doutorado em Contabilidade pela Universidade de Valência - Espanha \\ Professor da Universidade do Vale do Rio dos Sinos - UNISINOS \\ Av. Unisinos, 950. Bairro Cristo Rei. São Leopoldo/RS. CEP: 93022-000 \\ E-mail: clavarda@furb.br
}

\begin{abstract}
Alexandre Matos Pereira Mestrado em Ciências Contábeis pela Universidade Regional de Blumenau- FURB Rua Dr. Guilherme Gemballa, 13, Rio do Sul/SC E-mail: alexandrep@al.furb.br
\end{abstract}

\section{RESUMO}

Com vistas a auxiliar o processo de tomada de decisão no contexto organizacional, o planejamento e controle empresarial é uma ferramenta indispensável às organizações que pretendem obter uma vantagem competitiva. Assim, este estudo busca investigar o processo de tomada de decisão na Royal Ciclo, utilizando o planejamento e o controle orçamentário como uma ferramenta de apoio a gestão. Este estudo classifica-se como descritivo e qualitativo, por meio de um estudo de caso na empresa Royal Ciclo S/A. Os resultados evidenciam que a empresa apresenta flexibilidade para adaptação rápida ao entorno; o comportamento dos gestores não afeta as metas definidas, indicando como causas o reduzido número de gestores e o entrosamento e a periodicidade do acompanhamento; a empresa não utiliza sistemas de medição de performance envolvendo ativos intangíveis e criação de valor, mas de ferramentas consideradas tradicionais.

Palavras-chave: Planejamento e controle. Orçamento. Tomada de decisão.

\section{Business Budget Planning and Control as a Tool to Support Decision Making}

\section{ABSTRACT}

In order to assist the process of decision making in the organizational context, corporate planning and control is an indispensable tool for organizations seeking a competitive advantage. Thus, this study investigated the process of decision making in Royalciclo using the budget planning and control as a tool to support management. This study is classified as descriptive and qualitative, using a case study in the company Royal Cycle S/A. The results show that the company has the flexibility to adapt quickly to the environment, the behavior of managers does not affect the targets, indicating the small number of managers as causes, the rapport and frequency of monitoring; that company 
Planejamento e Controle orçamentário empresarial como Ferramenta de Apoio à Tomada de

Decisão

Carlos Eduardo Facin Lavarda, Alexandre Matos Pereira

does not use performance measurement systems involving intangible assets and value creation, but traditional tools.

Keywords: Planning and Control. Budget. Decision making.

\section{INTRODUÇÃO}

No intuito de buscar novas formas de aperfeiçoar a gestão e o desempenho organizacional, tendo em vista a ineficácia de várias metodologias e ferramentas destinadas à área administrativa e operacional das empresas, torna-se necessária a busca de novas abordagens que possibilitem a obtenção de vantagens competitivas frente à concorrência (SILVA et al., 2005). Assim, esta competitividade pode ser alcançada por meio do aperfeiçoamento do planejamento e controle empresarial, utilizando-o como ferramenta de apoio à tomada de decisão.

Neste sentido, Lopes e Blaschek (2005, p. 1) afirmam que "o processo orçamentário é o elemento principal do controle gerencial na maior parte das organizações, possuam elas fins lucrativos ou não". Welsch (1983, p. 21) define o planejamento e controle como "um enfoque sistemático e formal à execução das responsabilidades de planejamento, coordenação e controle da administração". Moreira (2002) destaca que o orçamento pode ser entendido como planejamento global da empresa que contempla um conjunto de planos e políticas formalmente estabelecido e expresso em resultados financeiros, que auxilia os gestores a conhecer os resultados operacionais da empresa e executar os acompanhamentos necessários, para que estes resultados sejam alcançados e os possíveis desvios sejam analisados, avaliados e corrigidos ao tempo que são detectados.

Neste contexto, surge a seguinte pergunta que norteia esta pesquisa: Como o planejamento e o controle orçamentário empresarial podem ser utilizados como ferramenta de apoio à tomada de decisão? Assim, busca-se investigar o processo de tomada de decisão na Royal Ciclo S/A, utilizando o planejamento e controle orçamentário como ferramenta de apoio a gestão. Tendo ainda como objetivos específicos: a) identificar as características do orçamento empresarial da Royal Ciclo $\mathrm{S} / \mathrm{A}$; b) verificar a vinculação entre o orçamento empresarial e o planejamento 
Planejamento e Controle orçamentário empresarial como Ferramenta de Apoio à Tomada de

Decisão

Carlos Eduardo Facin Lavarda, Alexandre Matos Pereira

estratégico na empresa investigada; e c) identificar situações em que o planejamento e o controle empresarial são utilizados como ferramenta de apoio à tomada de decisão.

Esta pesquisa justifica-se tendo em vista a importância em investigar o processo de planejamento e orçamento empresarial da empresa, e analisar seu nível de contribuição como ferramenta de gestão apoiando a tomada de decisão. Segundo Gonçalves e Silva (2006, p.2), "o orçamento não substitui o planejamento estratégico, mas é um apoio que a empresa tem para administrar o curto prazo, sem se esquecer do longo prazo". Souza (2007, p.17) destaca que "o processo de planejamento e orçamento está no coração da gestão de desempenho na maioria das organizações e deveria contribuir como uma ferramenta de vantagem competitiva".

Por outro lado, busca-se maior compreensão sobre o uso do orçamento em unidades singulares, já que apesar de ser um artefato há muito divulgado pela literatura, ainda é um tema pouco investigado no Brasil, conforme afirmam Leite et al. (2008, p.70), de que 'o tema 'orçamento' é muito pouco investigado entre a produção científica mais expressiva em Instituições de Ensino Superior".

O trabalho inicia com esta introdução. A seção 2 apresenta o referencial teórico que norteia a presente pesquisa. $\mathrm{Na}$ seção 3 apresentam-se os métodos e procedimentos adotados, além do roteiro utilizado na entrevista; na seção 4 realiza-se a análise e interpretação dos resultados; e por fim na seção 5 são apresentadas as considerações finais e as recomendações para pesquisas futuras.

\section{REFERENCIAL TEÓRICO}

Nesta seção aborda-se o planejamento e controle empresarial, além dos estudos anteriores realizados nesta temática.

\subsection{Planejamento e Controle Empresarial}

Diante do contexto atual de economia globalizada e acirramento da competição, o planejamento torna-se um importante instrumento competitivo. Horngren, Foster e Datar (2000, p.3) definem planejamento como "a escolha de metas, a previsão de 
resultados sobre vários caminhos de obtenção dessas metas e, por conseguinte, a decisão de como atingir as metas desejadas". Para tanto, Carpes et al. (2008) sugerem que "o planejamento se tornou uma ferramenta fundamental para as empresas, pois se deseja proceder de forma mais concisa e ágil, ordenando as atividades e coordenando recursos disponíveis (...) para atingir os objetivos estabelecidos". Já Castanheira (2008, p.29) destaca que "o planejamento deve ser visto como um processo contínuo que levará os gestores a indagações sobre o que fazer, como, quando, quanto, para quem e onde. Esses questionamentos vão promover o estabelecimento de formas para se atingir os objetivos empresariais".

Nesse sentido, Oliveira (2006, p.35) destaca que "o planejamento pode ser conceituado como um processo (...) desenvolvido para o alcance de uma situação futura desejada de um modo mais eficiente, eficaz e efetivo, com a melhor concentração de esforços e recursos pela empresa". Logo, Fischmann e Almeida (1991, p. 25) ressaltam que o "planejamento estratégico é uma técnica que, através da análise do ambiente de uma organização, cria consciência das suas oportunidades e ameaças dos seus pontos fortes e fracos para o cumprimento da sua missão". Já Oliveira (2006, p.35) o conceitua como "o estabelecimento de um conjunto de providências a serem tomadas pelo executivo para a situação em que o futuro tende a ser diferente do passado". Entretanto, Oliveira, (2007, p.73) admite que esta "é uma metodologia administrativa que permite estabelecer a direção a ser seguida pela empresa, e que visa ao maior grau de interação com o ambiente, no qual estão os fatores externos não controláveis pela empresa e para cada departamento dentro dela".

Assim, cabe ressaltar que o planejamento estratégico impacta diretamente no orçamento empresarial, onde Lunkes e Schnorrenberger (2009, p.52) atestam que "depois de saber qual é a base filosófica que norteia as ações da organização, aonde ela quer chegar, o que e como pretende alcançar seus propósitos, é chegada a hora de elaborar os planos de ação". Nesse sentido, Ribeiro (2004, p.23) destaca que "no âmbito organizacional, desde o momento em que o principal objetivo das empresas passou a ser a maximização do lucro, é que se tornou imperativo uma maior racionalidade dentro das empresas, visando assegurar a destinação previamente 
definida dos recursos disponíveis". Assim, o orçamento busca auxiliar no preenchimento desta lacuna, ou seja, na racionalização dos recursos.

Quanto ao controle empresarial, Atkinson et al. (2000, p.94) conceituam como "conjunto de métodos e instrumentos que os membros da empresa usam para mantê-la na trilha a fim de atingir seus objetivos". Consideram ainda que o controle possa ser utilizado sob dois enfoques, para assegurar obediência ou motivar as pessoas. Para assegurar obediência aos procedimentos operacionais "a informação é usada para motivar as pessoas a seguirem regras e verificar se elas estão seguindo-as", assim o orçamento é utilizado como ferramenta para assegurar o cumprimento de padrões estabelecidos na fase do planejamento, sem preocupar-se com os resultados globais da empresa ou eventuais oscilações do mercado.

Por outro lado, o controle orçamentário pode ser utilizado para promover a criatividade das pessoas e assim "ajudá-las a escolher um curso de ação que ajude a empresa a atingir seus objetivos" (ATKINSON et al., 2000, p.94). Logo, o controle não é coercitivo e está focando como as ações individuais de cada agente dentro da organização impactaram o resultado final da empresa, o que exige tanto flexibilidade para adaptarem-se as mudanças como responsabilidade.

Neste sentido, Bornia e Lunkes (2007, p.49) afirmam que "a empresa deve preocupar-se em controlar o que é importante e não se ater em demasia aos detalhes que pouco contribuem para geração de valor. As pessoas responsáveis pelos resultados devem participar ativamente da elaboração das metas orçamentárias, somente assim estarão comprometidas com o desempenho"

Frezatti (2008) considera que o planejamento e controle podem assumir diferentes perfis, especialmente quanto ao foco destinado exclusivamente às atividades de planejamento ou de controle. Assim, as empresas que enfatizam o planejamento mais que o controle nunca sabe o que realmente está acontecendo, pois, a realimentação do processo se torna difusa e improdutiva. Quando o foco são as atividades de controle, denota que a "gestão do negócio é casuística e repetitiva em termos de soluções e ações" (p. 20), sendo comum encontrar gerentes repletos de 
Planejamento e Controle orçamentário empresarial como Ferramenta de Apoio à Tomada de

Decisão

Carlos Eduardo Facin Lavarda, Alexandre Matos Pereira

relatórios com muitos números, mas sem nenhuma informação para a tomada de decisão.

Quando o foco é reduzido tanto nas atividades de planejamento quanto de controle, mostra-se uma atitude de vulnerabilidade, pela dificuldade de responder às demandas de mercado com agilidade. Já as empresas que apresentam significativa importância em ambas as atividades, tem-se uma organização "madura, com condições de desenvolver suas atividades de maneira consistente e relativamente mais segura" (FREZATTI, 2008, p.21).

\subsection{Estudos Anteriores}

Gonçalves e Silva (2006) analisaram as características pertinentes a utilização de um sistema de controle orçamentário em indústrias de bebidas, utilizando a estratégia de múltiplos casos. Dentre os resultados encontrados, perceberam que as duas empresas valorizavam o processo de controle orçamentário, envolvendo nele um grupo significativo de pessoas e de recursos computacionais, sendo que nenhuma das empresas apresentou resistência à utilização do sistema de controle orçamentário e buscavam utilizá-lo de forma integrada a outras ferramentas gerenciais. Destaca-se, ainda, que a participação dos gestores da baixa e média gerência na definição das estratégias era bastante restrita nas empresas investigadas.

Jones, Ribeiro e Rogers (2007) buscaram apresentar por meio de um estudo de caso, a relevância do Sistema de Informação Gerencial como ferramenta essencial no acompanhamento do resultado do exercício para auxiliar no processo de tomada de decisão, onde a Contabilidade atua como instrumento de informação para o planejamento e o controle financeiro. Dentre os resultados encontrados pode-se destacar: a utilização das informações orçamentárias para o processo de tomada de decisão, servindo como base para projeções futuras; o acompanhamento do orçamento permite que desvios ocorridos sejam conhecidos e corrigidos evitando novas incidências nos próximos períodos; o sistema de informações é um determinante no processo de gestão orçamentária, ao processar um grande volume de dados, sendo 
Planejamento e Controle orçamentário empresarial como Ferramenta de Apoio à Tomada de

Decisão

Carlos Eduardo Facin Lavarda, Alexandre Matos Pereira

utilizado como um veículo de informação e um poderoso instrumento de tomada de decisão.

Costa, Moritz e Machado (2007) buscaram identificar as contribuições do Orçamento Base Zero (OBZ) para o desenvolvimento do planejamento e do controle de resultados em organizações empresariais, por meio de um estudo de caso. Observaram que o OBZ não é simplesmente uma ferramenta para reduzir custos e garantir economias, mas procura a otimização dos recursos financeiros.

Raifur et al. (2008) abordaram o orçamento empresarial como ferramenta estratégica e de interatividade em organizações cooperativa, buscando identificar a relação entre o porte da cooperativa e a utilização do orçamento como ferramenta estratégica ou de controle. Verificaram que $58 \%$ das empresas analisadas utilizam o orçamento como ferramenta de apoio à estratégia da empresa, entretanto perceberam que as cooperativas menores têm uma percepção maior do orçamento como ferramenta de apoio à tomada de decisão. Ressalta-se que, ao aumentar a participação das pessoas na elaboração do orçamento aumenta a percepção do orçamento como uma ferramenta estratégica, embora não possa se afirmar que existe uma ampla participação das pessoas no processo de elaboração dos mesmos nas cooperativas.

\section{METODOLOGIA DA PESQUISA}

Este estudo classifica-se como descritivo, por meio de um estudo de caso. Segundo Gil (1999, p. 70), esta pesquisa tem como objetivo principal "descrever características de determinada população ou fenômeno ou estabelecimento de relações entre as variáveis". Na estratégia de Estudo de Caso "o pesquisador não tem controle sobre os eventos e variáveis, buscando aprender a totalidade de uma situação e, criticamente, descrever, compreender e interpretar a complexidade de um caso concreto" (MARTINS; THEÓPHILO, 2007, p.61). Assim, busca-se investigar o planejamento e o controle orçamentário que apóiam à tomada de decisão na Royal Ciclo S/A permitindo "uma investigação para se preservar as características holísticas e significativas dos eventos da vida real" (YIN, 2003, p. 21). 
A pesquisa faz uso de uma abordagem qualitativa. Martins e Theóphilo (2007, p.61) destacam que "a estratégia de pesquisa Estudo de Caso pede avaliação qualitativa, pois seu objetivo é o estudo de uma unidade social que se analisa profunda e intensamente". Os dados obtidos para análise possuem natureza primária, por meio de entrevistas. Segundo Richardson (1999), os dados primários de uma pesquisa são aqueles obtidos diretamente em campo.

As entrevistas foram realizadas no segundo semestre de 2009 na Royal Ciclo S/A, com auxílio de um roteiro estruturado apresentado no Quadro 1, que se baseou no questionário apresentado por Souza (2007). Na entrevista utilizou-se o roteiro estruturado composto por 14 perguntas abertas, sendo todas relacionadas ao planejamento e controle orçamentário empresarial como ferramenta de apoio à tomada de decisão, sendo respondidas na presença do entrevistador. As perguntas foram as seguintes:

1) Qual sua função/responsabilidade na empresa?

2) Qual é o número de funcionários da sua empresa?

3) Qual o faturamento anual da empresa?

4) Que software/ aplicação você utiliza para o processo de planejamento/orçamento. Você está satisfeito com a aplicação utilizada?

5) Qual a importância do planejamento/ orçamento para a sua empresa. Como você descreve o processo de planejamento/orçamento na sua empresa?

6) Qualquer desvio significativo em relação ao planejamento faz sua empresa implementar mudanças rapidamente?

7) As metas definidas para o orçamento podem levar a um comportamento inadequado dos gestores para atingi-las?

8) Nos últimos 2 anos, sua empresa propôs alguma mudança significativa no processo de planejamento/orçamento?

9) A visão, missão e os valores da sua organização são compartilhados entre todos os colaboradores? 
Planejamento e Controle orçamentário empresarial como Ferramenta de Apoio à Tomada de

Decisão

Carlos Eduardo Facin Lavarda, Alexandre Matos Pereira

10)O orçamento é consistente com os objetivos estratégicos. A estratégia da sua empresa é efetivamente/claramente comunicada para todos os indivíduos e grupos envolvidos no processo de planejamento?

11) $\mathrm{Na}$ sua organização, como o planejamento estratégico define as metas que deverão ser atingidas (destino), as principais ações que devem ser tomadas (direção) e o tempo para sua execução (velocidade)?

12)O planejamento financeiro está totalmente ligado ao planejamento estratégico através de metas operacionais derivadas dos objetivos estratégicos?

13)Quanto à gestão de desempenho, sua empresa utiliza ferramentas de medição e controle apropriadas. Quais ferramentas de gestão você utiliza atualmente?

14)Sua empresa utiliza sistemas de medição de performance envolvendo ativos intangíveis e criação de valor?

\section{ANÁLISE E INTERPRETAÇÃO DOS RESULTADOS}

Nesta seção são apresentadas a análise e interpretação dos dados que visam atingir os objetivos do presente estudo, sendo dividida em quatro tópicos: A primeira apresenta a caracterização da empresa investigada; na segunda constam as características do orçamento empresarial da Royal Ciclo; a terceira demonstra a vinculação entre o orçamento empresarial e o planejamento estratégico. E, por fim, na quarta busca-se identificar as situações em que o planejamento e o controle empresarial são utilizados como ferramenta de apoio à tomada de decisão.

\subsection{A Royal Ciclo S/A}

A Royal Ciclo S/A emprega 230 funcionários, sendo 172 diretos de produção, 40 indiretos e 18 na administração. Em 2008, faturou em torno de $R \$ 40$ milhões. Para 2009 havia previsão de aumento, mas após a crise mundial o objetivo passou a ser a manutenção de 2008. Foram entrevistados o Gerente Administrativo, Contador e Controller, Gerente Comercial e Gerente Industrial. 
Planejamento e Controle orçamentário empresarial como Ferramenta de Apoio à Tomada de Decisão

Carlos Eduardo Facin Lavarda, Alexandre Matos Pereira

\subsection{Características do Orçamento Empresarial da Royal Ciclo S/A}

Nessa seção apresenta-se: (i) o software utilizado no processo de planejamento/orçamento, bem como a satisfação de seus usuários; (ii) se desvios significativos em relação ao planejamento faz a empresa implementar as mudanças rapidamente; (iii) o comportamento dos gestores para atingir as metas definidas para 0 orçamento e (iv) quais as mudanças significativas ocorridas no orçamento nos últimos dois anos. A seguir, no Quadro 1 apresentam-se as respostas dos entrevistados. 


\begin{tabular}{|c|c|c|c|}
\hline PERGUNTAS & ENTREVISTADO 1 & ENTREVISTADO 2 & ENTREVISTADO 3 \\
\hline 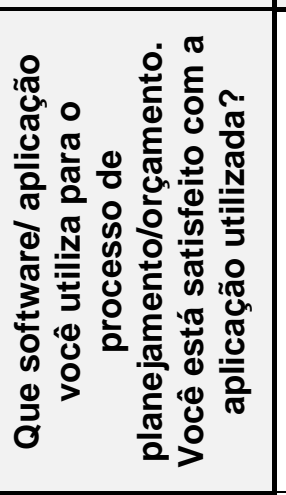 & $\begin{array}{l}\text { Software desenvolvido } \\
\text { especificamente para a } \\
\text { Royalciclo. Atende as áreas } \\
\text { de faturamento, fiscal, } \\
\text { contábil, compras, produção } \\
\text { e planej. /Orçamento. O } \\
\text { R.H. é terceirizado. O } \\
\text { software satisfaz as } \\
\text { necessidades da empresa, } \\
\text { porém as simulações são } \\
\text { feitas passando o orçamento } \\
\text { primeiro para o Excel. }\end{array}$ & $\begin{array}{c}\text { Temos um software } \\
\text { desenvolvido para nossa } \\
\text { empresa, em base } \\
\text { "windows" com } \\
\text { linguagem "clipper" que } \\
\text { atende as diversas áreas } \\
\text { que se comunicam, } \\
\text { porém, as informações } \\
\text { do planejamento são } \\
\text { restritas a } 4 \text { pessoas. } \\
\text { O Software atende as } \\
\text { necessidades existentes. }\end{array}$ & $\begin{array}{c}\text { Foi desenvolvido um software } \\
\text { internamente, e ele atende as } \\
\text { necessidades, mas o } \\
\text { orçamento muitas vezes não } \\
\text { consegue prever que } \\
\text { determinadas linhas não vão } \\
\text { emplacar no mercado, e daí } \\
\text { ele "fura" e é abandonado. }\end{array}$ \\
\hline 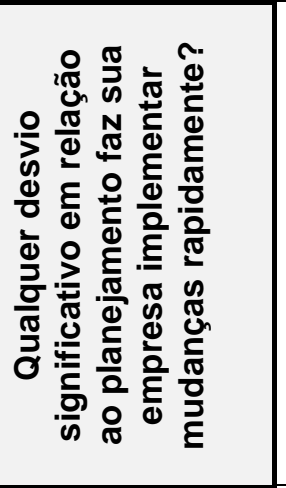 & $\begin{array}{l}\text { Em função da estrutura } \\
\text { organizacional ser enxuta, } \\
\text { permite mudanças rápidas } \\
\text { inclusive com uma } \\
\text { experiência recente em } \\
\text { janeiro de } 2009 \text { com a crise } \\
\text { mundial, onde houveram } \\
\text { demissões, realocação da } \\
\text { produçãa, e paralisação dos } \\
\text { investimentos. }\end{array}$ & $\begin{array}{l}\text { A nossa empresa tem } \\
\text { total rapidez para } \\
\text { implementações de } \\
\text { mudanças diante de } \\
\text { desvios, inclusive com } \\
\text { um caso recente da crise } \\
\text { mundial, fim de } 2008 \text { e } \\
\text { início de } 2009, \text { porém } \\
\text { diante da urgência e } \\
\text { tamanho do desvio, o } \\
\text { orçamento foi totalmente } \\
\text { abandonado. }\end{array}$ & $\begin{array}{l}\text { Os desvios acontecem e } \\
\text { frequentemente são feitas } \\
\text { reuniões para realocar a } \\
\text { produção, concessão de } \\
\text { férias, demissões, como em } \\
\text { um caso no início do ano, que } \\
\text { em função da crise } \\
\text { econômica geraram } \\
\text { mudanças rápidas e } \\
\text { drásticas. }\end{array}$ \\
\hline 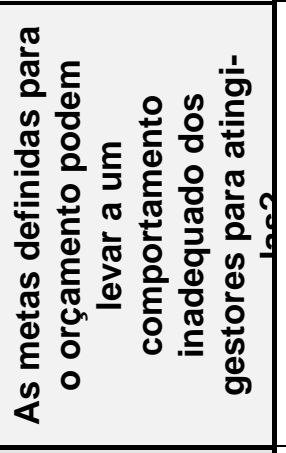 & $\begin{array}{l}\text { Pelo motivo de uma } \\
\text { estrutura de gestão bem } \\
\text { reduzida e frequentemente } \\
\text { avaliada em parâmetros } \\
\text { definidos em sistema, que } \\
\text { permite alterações de metas } \\
\text { em curto prazo, impossibilita } \\
\text { comportamentos } \\
\text { inadequados. }\end{array}$ & $\begin{array}{l}\text { Não é o tipo de problema } \\
\text { que afete nossa } \\
\text { empresa, pois o } \\
\text { entrosamento dos nossos } \\
\text { gestores é grande, pelo } \\
\text { fato da estrutura de } \\
\text { gestão que temos de ser } \\
\text { bem reduzida, } \\
\text { possibilitando um } \\
\text { alinhamento das } \\
\text { decisões tomadas. } \\
\end{array}$ & $\begin{array}{c}\text { Não, em função da } \\
\text { periodicidade que são feitos } \\
\text { os acompanhamentos e } \\
\text { passadas as informações no } \\
\text { caso de dados novos, a } \\
\text { pequena estrutura } \\
\text { administrativa permite um } \\
\text { bom nível de interação com a } \\
\text { produção evitando essas } \\
\text { falhas. }\end{array}$ \\
\hline 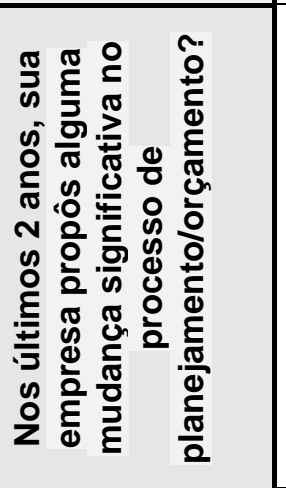 & $\begin{array}{l}\text { A empresa vem adotando o } \\
\text { mesmo modelo desde a } \\
\text { fusão com a Selle Royal em } \\
2005 \text {, o planejamento e } \\
\text { orçamento tradicional. } \\
\text { Existe o interesse envolver } \\
\text { mais os níveis hierárquicos } \\
\text { no planejamento e ainda } \\
\text { buscar melhorias estudando } \\
\text { a utilização do BSC que já } \\
\text { acontece na empresa } \\
\text { Italiana que é sua sócia. }\end{array}$ & $\begin{array}{c}\text { Desde } 2005 \text { a empresa } \\
\text { utiliza o mesmo modelo } \\
\text { que vem tendo mudanças } \\
\text { gradativas em função da } \\
\text { experiência que se } \\
\text { adquire com a sua } \\
\text { utilização. }\end{array}$ & $\begin{array}{l}\text { Nos últimos anos a empresa } \\
\text { tem adotado o mesmo } \\
\text { processo de planejamento e } \\
\text { orçamento }\end{array}$ \\
\hline
\end{tabular}

Quadro 1 - Características do Orçamento da Royal Ciclo S/A Fonte: Dados da pesquisa. 
Planejamento e Controle orçamentário empresarial como Ferramenta de Apoio à Tomada de Decisão

Carlos Eduardo Facin Lavarda, Alexandre Matos Pereira

A gestão do processo orçamentário é realizada por um software específico desenvolvido internamente que atende as necessidades da empresa, apesar de em alguns momentos acusar a necessidade de uso de planilhas eletrônicas para simulações auxiliares ou de ser parcialmente utilizado em algumas linhas de produtos.

Observou-se que os gestores não se mantêm fixamente no plano orçado sempre que ocorram mudanças no mercado que exigem novas decisões, como demissões, redução de produção e reprogramação de férias. Neste ponto, a empresa apresenta flexibilidade para adaptação rápida ao entorno, como observam Lunkes e Schnorrenberger (2009). Quanto ao comportamento inadequado dos gestores para alcançar as metas orçamentárias, uma das principais críticas realizadas ao sistema orçamentário (FREZATTI, 2008), a empresa pesquisada mostra que este tipo de problema não a afeta, indicando como causas o reduzido número de gestores, o entrosamento e a periodicidade do acompanhamento.

\subsection{Vínculos entre o Orçamento Empresarial e o Planejamento Estratégico}

Buscando atender ao segundo objetivo específico, dividiu-se esta subseção em quatro itens, sendo eles: (i) a importância do planejamento/orçamento para a empresa; (ii) a visão, missão e os valores praticados pela organização são compartilhados com seus funcionários?; (iii) o orçamento está alinhado aos objetivos estratégicos da empresa investigada; e (iv) o planejamento financeiro está ligado ao planejamento estratégico por meio de metas operacionais, de acordo com as informações apresentadas no Quadro 2. 


\begin{tabular}{|c|c|c|c|}
\hline PERGUNTAS & ENTREVISTADO 1 & ENTREVISTADO 2 & ENTREVISTADO 3 \\
\hline 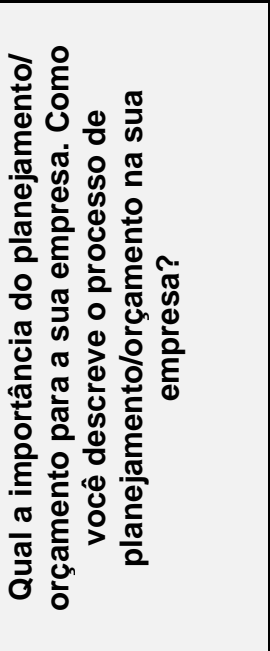 & $\begin{array}{l}\text { Participam o diretor, os gerentes } \\
\text { comercial, industrial e } \\
\text { administrativo, iniciando pelas } \\
\text { informações da área comercial } \\
\text { com as expectativas de mercado, } \\
\text { após com a produção para análise } \\
\text { das possibilidades de atendimento } \\
\text { com o envolvimento em reuniões } \\
\text { específicas dos coordenadores de } \\
\text { produção, e em seguida as } \\
\text { decisões de investimento, assim } \\
\text { se materializando o orçamento } \\
\text { que é feito para } 5 \text { anos com } \\
\text { revisões anuais, e com os seu } \\
\text { ciclos de julho a junho em função } \\
\text { da Selle Royal, empresa Italiana } \\
\text { sócia em } 50 \% \text { do capital social da } \\
\text { Royalciclo. }\end{array}$ & $\begin{array}{l}\text { A diretoria junto com os } \\
\text { gerentes administrativo, } \\
\text { comercial e industrial, realiza } \\
\text { reuniões específicas de } \\
\text { planejamento e orçamento. } \\
\text { São nessas reuniões que são } \\
\text { definidos os parâmetros para } \\
\text { os próximos } 5 \text { anos, com } \\
\text { todas as ações para atingir as } \\
\text { metas propostas, portanto de } \\
\text { suma importância. }\end{array}$ & $\begin{array}{c}\text { A sua importância se da } \\
\text { principalmente na } \\
\text { determinação de parâmetros } \\
\text { iniciais para a atividade da } \\
\text { empresa. } \\
\text { O diretor apresenta as } \\
\text { premissas advindas de seus } \\
\text { contatos com a sócia } \\
\text { empresa italiana Selle Royal, } \\
\text { em reuniões com os } \\
\text { gerentes da área comercial, } \\
\text { industrial e administrativa, } \\
\text { onde são definidas todas as } \\
\text { metas e por fim o orçamento, } \\
\text { que é feito para cinco anos } \\
\text { com revisões anuais. }\end{array}$ \\
\hline 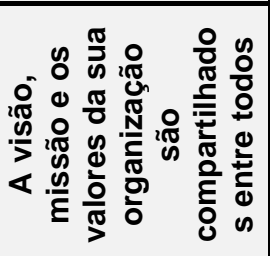 & $\begin{array}{l}\text { Ainda não existe um nível } \\
\text { adequado de comunicação para } \\
\text { todos, pelo menos de maneira } \\
\text { formal, mas existe essa intenção } \\
\text { de envolver todos com a visão, } \\
\text { missão e valores da empresa. }\end{array}$ & $\begin{array}{c}\text { Esta ainda é uma falha grande } \\
\text { que temos, estamos } \\
\text { estudando uma maneira de } \\
\text { comunicar o staff sobre } \\
\text { nossas metas e sonhos para o } \\
\text { futuro. }\end{array}$ & $\begin{array}{l}\text { Não esta escrito de maneira } \\
\text { formal e fica restrito aos } \\
\text { níveis hierárquicos } \\
\text { superiores em função das } \\
\text { reuniões. }\end{array}$ \\
\hline 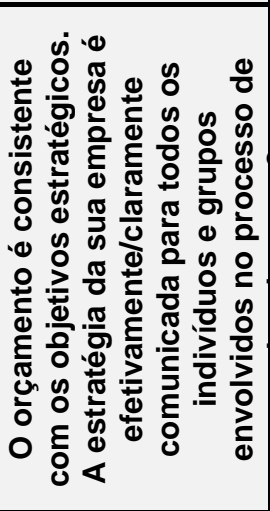 & $\begin{array}{l}\text { Sim, o orçamento justamente é } \\
\text { proveniente das reuniões } \\
\text { estratégicas. } \\
\text { A estratégia não é claramente } \\
\text { comunicada para todos, pois } \\
\text { ainda estamos estudando qual o } \\
\text { nível máximo possível de } \\
\text { informações devem e podem ser } \\
\text { compartilhadas, sem que venha } \\
\text { causar instabilidades no clima } \\
\text { organizacional da empresa. }\end{array}$ & $\begin{array}{c}\text { O orçamento se materializa a } \\
\text { partir das reuniões } \\
\text { estratégicas, é dividido em } \\
\text { peças que são divulgadas } \\
\text { para as áreas específicas. } \\
\text { A estratégia da empresa não é } \\
\text { repassada a todos os grupos, } \\
\text { existe uma certa cautela com } \\
\text { essas informações, que } \\
\text { podem atrapalhar o bom } \\
\text { andamento das atividades. } \\
\text { Mas temos estudado } \\
\text { possibilidades de melhorar } \\
\text { essa comunicação. }\end{array}$ & $\begin{array}{c}\text { Os objetivos estratégicos } \\
\text { são definidos nas reuniões } \\
\text { da alta administração, que } \\
\text { de certa forma repassam as } \\
\text { suas áreas específicas, mas } \\
\text { as informações ainda não } \\
\text { chegam para todos os níveis } \\
\text { hierárquicos. }\end{array}$ \\
\hline 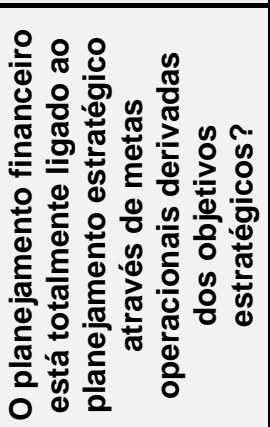 & $\begin{array}{c}\text { É elaborado o orçamento de caixa } \\
\text { derivado das metas operacionais } \\
\text { que após é comparado com o } \\
\text { fluxo de caixa realizado, isso é } \\
\text { feito por profissional responsável, } \\
\text { observado diariamente pelo } \\
\text { diretor. }\end{array}$ & $\begin{array}{c}\text { Estabelecidos as metas e } \\
\text { objetivos estratégicos, são } \\
\text { preparados os orçamentos, } \\
\text { inclusive o orçamento de caixa } \\
\text { que é acompanhado } \\
\text { diariamente pelo Diretor da } \\
\text { empresa. }\end{array}$ & $\begin{array}{c}\text { O orçamento de caixa é feito } \\
\text { com base nos demais } \\
\text { orçamentos, que estão } \\
\text { ligados nas metas } \\
\text { operacionais e é } \\
\text { acompanhado pelo diretor } \\
\text { da empresa e realizado por } \\
\text { pessoa responsável pelo } \\
\text { setor financeiro. }\end{array}$ \\
\hline
\end{tabular}

Quadro 2: Vínculos entre o orçamento empresarial e o planejamento estratégico Fonte: Dados da pesquisa. 
Planejamento e Controle orçamentário empresarial como Ferramenta de Apoio à Tomada de

Decisão

Carlos Eduardo Facin Lavarda, Alexandre Matos Pereira

Quanto ao processo de planejamento e orçamento na empresa, observou-se que a diretoria, junto com o gerente administrativo, comercial e industrial, realiza reuniões específicas de planejamento e orçamento, onde são definidos os parâmetros para os próximos 5 anos, e as ações para atingir as metas propostas, em consonância com a empresa italiana Selle Royal, sócia em $50 \%$ do capital social da Royal Ciclo. O uso do orçamento observado na empresa é enfatizado por Frezatti et al. (2007), que afirmam que o orçamento é o artefato com maior demanda na Contabilidade Gerencial.

A visão, missão e os valores da organização não são compartilhados entre todos os colaboradores, assim como não está expresso formalmente e ficam restritos aos níveis hierárquicos superiores.

Os entrevistados confirmam que o orçamento é consistente com os objetivos estratégicos, apesar de que a estratégia não é claramente comunicada para todos os níveis. Por outro lado, afirmam que se encontra em estudos qual o nível máximo possível de informações que devem e podem ser compartilhadas, sem que venha causar instabilidades no clima organizacional da empresa.

Verificou-se, como exemplo do vínculo entre o orçamento empresarial e o planejamento estratégico, que o planejamento do caixa está totalmente ligado ao planejamento estratégico através de metas operacionais derivadas dos objetivos estratégicos e é acompanhado pelo diretor da empresa e realizado por pessoa responsável pelo setor financeiro.

\subsection{Utilização do Planejamento e o Controle Empresarial como Ferramenta de} Apoio à Tomada de Decisão

Para atender ao terceiro objetivo específico, dividiu-se esta subseção em três partes: (i) o planejamento estratégico define as metas que deverão ser atingidas (destino), as principais ações que devem ser tomadas (direção) e o tempo para sua execução (velocidade) na organização; (ii) a gestão de desempenho da empresa utiliza ferramentas de medição e controle apropriadas; e (iii) a empresa utiliza sistemas de medição de performance que envolve ativos intangíveis e criação de valor, segundo as informações do Quadro 3. 
Planejamento e Controle orçamentário empresarial como Ferramenta de Apoio à Tomada de

Decisão

Carlos Eduardo Facin Lavarda, Alexandre Matos Pereira

\begin{tabular}{|c|c|c|c|}
\hline PERGUNTAS & ENTREVISTADO 1 & ENTREVISTADO 2 & ENTREVISTADO 3 \\
\hline 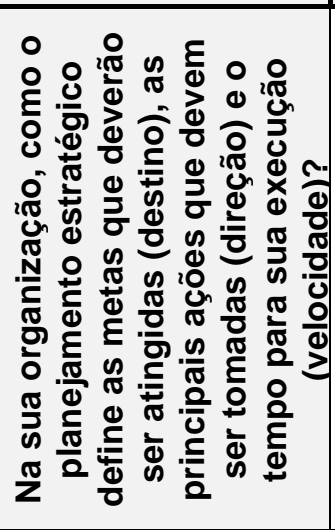 & $\begin{array}{c}\text { Com vistas no mercado, } \\
\text { são definidos os } \\
\text { investimentos junto com } \\
\text { a investidora Selle } \\
\text { Royal, e em reuniões } \\
\text { subseqüentes } \\
\text { delimitadas as metas e } \\
\text { ações para atingir esse } \\
\text { mercado alvo, com a } \\
\text { materialização do } \\
\text { orçamento dentro de } \\
\text { cinco anos e revisões } \\
\text { anuais destes. }\end{array}$ & $\begin{array}{l}\text { Em reuniões específicas são } \\
\text { definidas as metas e ações } \\
\text { para serem tomadas para um } \\
\text { período de } 5 \text { anos, sempre } \\
\text { acrescentando o último ano e } \\
\text { revisando o próximo que já } \\
\text { está feito. }\end{array}$ & $\begin{array}{c}\text { Após as reuniões do } \\
\text { diretor com a empresa } \\
\text { investidora e em } \\
\text { seguida com as áreas } \\
\text { comercial, industrial e } \\
\text { administrativa, são } \\
\text { definidas as metas e } \\
\text { ações a serem tomadas } \\
\text { dentro de um período } \\
\text { de cinco anos, com } \\
\text { revisões feitas a cada } \\
\text { ano. }\end{array}$ \\
\hline 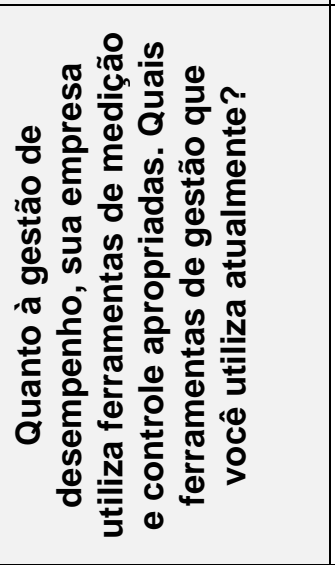 & $\begin{array}{c}\text { São utilizadas as } \\
\text { ferramentas comuns, } \\
\text { balanço patrimonial, } \\
\text { DRE, fluxo de caixa, } \\
\text { análise de lucratividade } \\
\text { por produto, margem de } \\
\text { contribuição, sempre } \\
\text { comparando orçado } \\
\text { com realizado. } \\
\text { O sistema permite o } \\
\text { gerenciamento das } \\
\text { vendas, produção, } \\
\text { compras, estoques e } \\
\text { etc. }\end{array}$ & $\begin{array}{l}\text { As ferramentas de medição e } \\
\text { controle são as tradicionais, } \\
\text { balanço, demonstração de } \\
\text { resultado, fluxo de caixa, } \\
\text { margem de contribuição por } \\
\text { produto. } \\
\text { Acompanhamento via } \\
\text { sistema da produção, } \\
\text { vendas, estoques, pedidos. }\end{array}$ & $\begin{array}{c}\text { Na área industrial, a } \\
\text { produtividade é medida } \\
\text { por funcionário através } \\
\text { de relatórios diários e } \\
\text { nas demais áreas são } \\
\text { utilizadas as } \\
\text { ferramentas } \\
\text { tradicionais, como } \\
\text { balanço, DRE, fluxo de } \\
\text { caixa e demais } \\
\text { controles feitos com o } \\
\text { sistema. }\end{array}$ \\
\hline 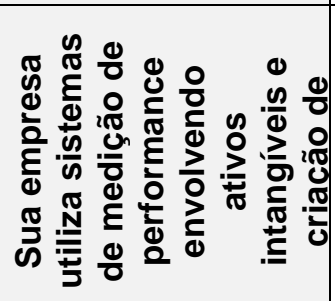 & $\begin{array}{c}\text { Por enquanto não } \\
\text { utiliza. }\end{array}$ & Não utiliza & Não utiliza. \\
\hline
\end{tabular}

Quadro 3: Utilização do Planejamento e do Controle Empresarial como Ferramenta de Apoio à Tomada de Decisão

Fonte: Dados da pesquisa.

Quanto à definição de metas, a partir do planejamento estratégico; principais ações que devem ser tomadas e tempo para sua execução verificou-se que estas são definidas junto com a investidora Selle Royal, sempre a partir da observação do mercado, e em reuniões subseqüentes são delimitadas as metas e ações para atingir esse mercado alvo, com a materialização do orçamento.

Quanto à gestão de desempenho, a produtividade na área industrial é medida por funcionário, através de relatórios diários, e nas demais áreas são utilizadas as 
Planejamento e Controle orçamentário empresarial como Ferramenta de Apoio à Tomada de

Decisão

Carlos Eduardo Facin Lavarda, Alexandre Matos Pereira

ferramentas tradicionais, como Balanço Patrimonial, Demonstração do Resultado do Exercício, Fluxo de Caixa e demais controles feitos com o sistema de gestão. Por outro lado, observou-se que a empresa não utiliza sistemas de medição de performance envolvendo ativos intangíveis e criação de valor.

\section{CONSIDERAÇÕES FINAIS}

Considerando que o planejamento e o controle orçamentário são instrumentos imprescindíveis ao processo de tomada de decisão, o presente trabalho objetivou investigar o processo de tomada de decisão na Royal Ciclo S/A, utilizando o planejamento e controle orçamentário como uma ferramenta de gestão. Esse objetivo foi atingido no momento em que os objetivos específicos deste estudo foram contemplados por meio da análise realizada.

Em resposta a pergunta de pesquisa sobre como o planejamento e o controle orçamentário empresarial podem ser utilizados como uma ferramenta de apoio à tomada de decisão, pode se identificar que processo orçamentário é apoiado por um software específico e a empresa apresenta flexibilidade para adaptação rápida ao entorno. O comportamento dos gestores não afeta a definição de metas orçamentárias, indicando como causas o reduzido número de gestores, o entrosamento e a periodicidade do acompanhamento; os parâmetros para os próximos 5 anos, e as ações para atingir as metas propostas são definidos entre a diretoria, e os gerentes administrativo, comercial e industrial.

Também se verificou que a visão, missão e os valores da organização não são compartilhados entre todos os colaboradores, mas somente ao nível de diretoria. O orçamento é consistente com os objetivos estratégicos e o planejamento do caixa está totalmente ligado ao planejamento estratégico mediante metas operacionais. As principais ações que devem ser tomadas pela organização e o tempo para sua execução são definidos a partir da observação do mercado, e em reuniões subseqüentes são delimitadas as metas e ações para atingir esse mercado alvo, com a materialização do orçamento. 
Planejamento e Controle orçamentário empresarial como Ferramenta de Apoio à Tomada de

Decisão

Carlos Eduardo Facin Lavarda, Alexandre Matos Pereira

A produtividade na área industrial é medida por funcionário, através de relatórios diários, e nas demais áreas são utilizadas as ferramentas tradicionais, como análise do resultado, indicadores operacionais e financeiros, sendo que na empresa não se utiliza sistemas de medição de performance envolvendo ativos intangíveis e criação de valor.

Para realizar pesquisas futuras sobre este tema, sugere-se ampliar o número de casos estudados, com empresas de mesmo porte e ramo, para identificar características comuns que auxiliem na compreensão do uso do orçamento empresarial, como artefatos de planejamento e controle no processo de tomada de decisão.

\section{REFERÊNCIAS}

ATKINSON, A. A.; BANKER, R. D.; KAPLAN, R. S.; YOUNG, S. M. (2000). Contabilidade Gerencial. São Paulo: Atlas.

BORNIA, Antonio Cezar; LUNKES, Rogério João. (2007). Uma Contribuição à Melhoria do Processo Orçamentário. Contabilidade Vista \& Revista, v. 18, n. 4, p. 37-59, out./dez.

CARPES, A. M. S.; ORO, I. M.; EIDT, J.; STERZ, R. (2008). Orçamento empresarial: uma investigação sobre as formas de acompanhamento orçamentário utilizadas pelas companhias catarinenses. In: Congresso Brasileiro de Custos, 5., Curitiba, PR, Brasil, 12 a 14 de novembro de 2008. Anais... Fortaleza: CIC. CD-ROM.

CASTANHEIRA, Dariane Reis Fraga. (2008). O Uso do Orçamento Empresarial como Ferramenta de Apoio à Tomada de Decisão e ao Controle Gerencial em Indústrias Farmacêuticas de Médio Porte. 111f. (Dissertação de Mestrado). Programa de PósGraduação em Administração, Universidade de São Paulo. Faculdade de Economia, Administração e Contabilidade, São Paulo.

COSTA, Alexandre Marino; MORITZ, Gilberto de Oliveira; MACHADO, Filipe Menezes Vasconcellos. (2007). Contribuições do Orçamento Base Zero (OBZ) no Planejamento e Controle de Resultados em Organizações Empresarias. Revista Contemporânea de Contabilidade, v.1, n. 8, p.85-98, jul./Dez.

FISCHMANN, Adalberto A.; ALMEIDA, Martinho Isnard R. (1991). Planejamento Estratégico na Prática. São Paulo: Atlas.

FREZATTI, F. (2008). Orçamento Empresarial: Planejamento e Controle Gerencial. São Paulo: Atlas. 
Planejamento e Controle orçamentário empresarial como Ferramenta de Apoio à Tomada de

Decisão

Carlos Eduardo Facin Lavarda, Alexandre Matos Pereira

FREZATTI, Fábio; GUERREIRO, Reinaldo; AGUIAR, Andson Braga de; GOUVÊA, Maria Aparecida. (2007). Análise do Relacionamento entre a Contabilidade Gerencial e o Processo de Planejamento. RAC, 2a. Edição Especial, p. 33-54.

GIL, A. C. (1999). Métodos e técnicas de pesquisa social. São Paulo: Atlas.

GONÇALVES, Rosana Carmen de Meiroz Grilho; SILVA, Adriana Cristina. (2006). Caracterização do Uso do Sistema de Controle Orçamentário em Indústria de Bebidas Estudo de Caso Múltilo. In: Congresso Brasileiro de Custos, 13., 2006, Belo Horizonte. Anais... Belo Horizonte: CBC. CD-ROM.

HORNGREN, C. T.; FOSTER, G.; DATAR, S. M. (2000). Contabilidade de Custos. (9 ed.). Rio de Janeiro: LTC.

JONES, Graciela Dias Coelho; RIBEIRO, Kárem Cristina de Sousa; ROGERS, Pablo. (2007). Proposta de um modelo-síntese para planejamento e controle orçamentário: Estudo de caso em uma empresa industrial. In: Congresso Brasileiro de Custos, 14. João Pessoa. Anais... João Pessoa: CBC. CD-ROM.

KOONTZ, Harold; O'DONNELL, Cyril. (1968). Principles of Management and analysis of managerial functions. (4 ed.). New York: McGraw-Hill.

LEITE, Rita Mara; CHEROBIM, Ana Paula Mussi Szabo; SILVA, Helena de Fátima Nunes; BUFREM, Leilah Santiago. (2008). Orçamento Empresarial: Levantamento da Produção Científica do Período de 1995 a 2006. Revista Contabilidade e Finanças, USP, São Paulo, v. 19, n. 47, p. 56 - 72, maio/agosto.

LOPES, Hilton de Araújo; BLASCHEK, José Roberto. (2005). Orçamento empresarial: manter, aperfeiçoar ou abandonar? In: Congresso Internacional de Custos, 9. Florianópolis. Anais... Florianópolis: CIC. CD-ROM.

LUNKES, R. J.; SCHNORRENBERGER, D. (2009). Controladoria na Coordenação dos Sistemas de Gestão. São Paulo: Atlas.

MARTINS, Gilberto de Andrade; THEÓPHILO, Carlos Renato. (2007). Metodologia da Investigação Científica para Ciências Sociais Aplicadas. São Paulo: Atlas.

MOREIRA, José Carlos. (2002). Orçamento empresarial: manual de elaboração. (5 ed.). São Paulo: Atlas.

OLIVEIRA, Antônio Benedito Silva (Coordenação). (2003). Métodos e técnicas de pesquisa em contabilidade. São Paulo: Saraiva.

OLIVEIRA, Djalma de Pinho Rebouças. (2007). Administração Estratégica na Prática. São Paulo: Atlas. 
São Paulo: Atlas.

(2006). Planejamento Estratégico: Conceitos, Metodologia e Práticas.

RAIFUR, Léo et al. (2008). Orçamento em cooperativas agropecuárias da região sul do Brasil: ferramenta estratégica e de interatividade. In: Congresso Brasileiro de Custos, 15. Curitiba. Anais... Curitiba: CBC. CD-ROM.

RIBEIRO, Bianca Kwiatkowski. (2004). Alinhamento Estratégico do Planejamento Orçamentário nas Organizações: o caso da CBTU. 102f. (Dissertação de Mestrado). Programa de Pós-Graduação em Administração, Pontifícia Universidade Católica do Rio de Janeiro, Rio de Janeiro.

RICHARDSON, R. J. (1999). Pesquisa social: métodos e técnicas. (3 ed.). São Paulo: Atlas.

SILVA, José A. B. et al. (2005). As medidas de desempenho como ferramenta de gerenciamento. In: Congresso Nacional de Estudantes de Engenharia Mecânica, 12. São Paulo. Anais... São Paulo: ABCM. CD-ROM.

SOUZA, Cláudio Peternella. (2007). Um estudo exploratório sobre o Planejamento e Orçamento Empresarial. 167 f. (Dissertação de Mestrado). Programa de PósGraduação em Ciências Contábeis e Financeiras, Pontifícia Universidade Católica de São Paulo, São Paulo.

WELSCH, Glenn A. (1983). Orçamento Empresarial. São Paulo: Atlas.

YIN, R.K. (2003). Estudo de caso: planejamento e métodos. São Paulo: Bookman.

Data de Submissão: 22/04/2010

Data de Aceite: 11/03/2011 